\title{
The WERO group stop smoking competition: main outcomes of a pre- and post- study
}

\author{
Marewa Glover ${ }^{1 *}$, Anette Kira ${ }^{1}$, Dudley Gentles ${ }^{1}$, Nathan Cowie ${ }^{1}$, Chris Paton $^{2}$ and Warren Moetara ${ }^{3}$
}

\begin{abstract}
Background: One potential promising strategy for increasing smoking cessation for Māori (Indigenous New Zealanders) and New Zealand resident Pacific Island people is Quit and Win competitions. The current uncontrolled pre and post study, WERO (WERO in Māori language means challenge), differs from previous studies in that it aims to investigate if a stop smoking contest, using both within team support, external support from a team coach and cessation experts, and technology, would be effective in prompting and sustaining quitting.

Method: Fifteen teams, recruited from urban Māori, rural Māori and urban Pacific communities, competed to win a $\mathrm{NZ} \$ 5000$ (about $€ 3,000, £ 2600$ ) prize for a charity or community group of their choice. People were eligible if they were aged 18 years and over and identified as smokers. Smoking status was biochemically validated at the start and end of the 3 month competition. At 3-months post competition self-reported smoking status was collected.

Results: Fourteen teams with 10 contestants and one team with eight contestants were recruited. At the end of the competition the biochemically verified quit rate was 36\%. The 6 months self-reported quit rate was $26 \%$. The Pacific and rural Māori teams had high end of competition and 6 months follow-up quit rates (46\% and 44\%, and $36 \%$ and 29\%).

Conclusion: WERO appeared to be successful in prompting quitting among high smoking prevalence groups. WERO combined several promising strategies for supporting cessation: peer support, cessation provider support, incentives, competition and interactive internet and mobile tools. Though designed for Māori and Pacific people, WERO could potentially be effective for other family- and community-centred cultures.
\end{abstract}

Keywords: Smoking cessation, Team quit and win contest, Indigenous people, Culturally informed

\section{Background}

Several countries, including Australia, Finland, New Zealand, Singapore and Scotland, have reached low smoking prevalence (less than $20 \%$ of the general population) [1-5] and some have set goals to become smokefree. New Zealand's near gold-standard tobacco control programme of regular tobacco tax increases, ongoing extensions to smokefree environments and tobacco product marketing bans, a free national Quitline and subsidised cessation products, has decreased daily smoking prevalence from $25 \%$ in 1996/1997 [2] to $15 \%$ in 2013 [6]. However, substantial socioeconomic and ethnic disparities in smoking persist: $15 \%$ of European New Zealanders are daily smokers, 38\% of Māori (Indigenous New Zealanders,

\footnotetext{
*Correspondence: m.glover@auckland.ac.nz

${ }^{1}$ Centre for Tobacco Control Research, Social and Community Health, University of Auckland, Auckland, New Zealand

Full list of author information is available at the end of the article
}

$15 \%$ of the population) and $23 \%$ Pacific Island people are daily smokers [2]. The New Zealand government's aspirational goal is to be smokefree by 2025 , defined as "a smoking prevalence of less than $5 \%$, with tobacco being difficult to obtain and children not exposed to smoking" [7]. The 2018 midterm goal is to reduce the overall daily smoking prevalence to less than $10 \%$ and halve Māori and Pacific Island daily smoking prevalence to $19 \%$ and $11.5 \%$ respectively [8]. At the current cessation rate (supported and unsupported) of 3\% per year [9], the Smokefree 2025 goals will not be reached. To achieve Smokefree 2025 and swiftly reduce smoking related harms, innovative strategies that can assist more smokers to more effectively quit will be needed.

The Ministry of Health's key approach to reduce smoking prevalence is to increase quit rates by triggering more supported quit attempts more often [10]. To increase supported quitting among Māori, Pacific Island and low 
socioeconomic smokers a number of barriers to use of cessation support and products need to be addressed [11]. These barriers include a lack of knowledge, or incorrect knowledge of, cost or difficulty in accessing, low belief in the efficacy of, and low attractiveness of cessation products and services [12]. Designing public health interventions consistent with the cultural beliefs and practices of target populations is believed to lead to better receptivity, acceptance and salience of health information and programs [13].

Māori and Pacific Island cultures are family-centred with strong ties to their island and tribal identities which are maintained through culturally-based community-centres and groups and for Māori, language based schooling including pre-schools, and for Pacific, churches. Moreover, Māori and Pacific people have higher participation rates in organised competitions and events than New Zealand European people (44\%, 41\%, and 38\% respectively) [14]. Māori cultural contests such as kapa haka (Māori performing arts) are well-attended and popular [15] and Pacific cultural competitions such as kilikiti (a form of cricket) claim high participation rates [16]. These contests incorporate inter-family, church or tribe competitiveness, are culturally-centred and encourage community participation-all factors identified as key components for effective recruitment and health intervention success for indigenous people [17].

Qualitative research with Māori and Pacific smokers identified that Quit and Win competitions are a potentially promising and attractive strategy for prompting cessation [18]. Although Quit and Win competitions vary, they often have these common elements: biochemical validation of smoking status, contest promoted in media and in participants' community, winning a prize and support from health professionals [19]. However, the long-term efficacy of Quit and Win contests is inconclusive, with Quit and Win competitions delivering short-term quit rates ranging from $8 \%$ to $20 \%[19,20]$. Furthermore, Quit and Win contests that rely on self-reported abstinence may suffer high deception rates and hence biochemical validation of abstinence claims are preferable [21]. The vast majority of Quit and Win competitions pitch individuals against each other [19]. A few workplace competitions published in the 1980s included teams, as opposed to individuals. All the studies had high end-of-competition rates for competition groups (39\% [22], 22\% [23], and 50\% [24]). None of those studies achieved a significant higher quit rate at follow-up for the competition versus control group. However, in the area of obesity, research has found that group-based is more effective than individual-based competition and that the difference was maintained long term [25-27].

Despite the suggestion that social support influences intention to quit and maintenance of smokefree status
[28] it has been underused in cessation interventions [29]. However, social support has been used and been found to have a positive influence on cessation when combined with Quit and Win competitions [30,31]. Contestants in Quit and Win contests who have a support person are more likely to quit and remain abstinent than those who do not have a support person [32]. One study found that $60 \%$ of their contestants utilised a designated support person, which reflects the importance of this type of support $[32,33]$. A pilot New Zealand contest that was run in 2000 also found that one of the factors associated with quit success was if the contestant had identified a support person [34]. The strategies for including social support have varied between different contests. For example, Pirie et al. [32] incorporated the social support into the contest, where the support person also got a prize if the smoker quit (but the support person was not a contestant themselves). A different strategy used by Croghan et al. [33] was to have two contests for one community - a Quit and Win contest for smokers and a Support Quit and Win for supporters.

\section{The current study}

In order to reach the goal of Smokefree 2025, the New Zealand Ministry of Health's key approach is to trigger more supported quit attempts. To date, as far as we can tell, Quit and Win competitions have not been adapted to include cultural elements, such as focusing on family or community groups and invoking existing inter-tribal rivalry to increase the attractiveness or relevancy for different ethnic groups [35]. By increasing attractiveness and thereby enrolment in cessation interventions it is possible to overcome some of the barriers to cessation, such as lack of knowledge and low attractiveness of cessation products. Furthermore, previous studies have identified the need for social support in Quit and Win contests, however, those studies incorporated a noncontestant to support a contestant. The previous studies that incorporated the support into a team contest are over 20 years old and were only tested in a work environment. The current uncontrolled pre and post study differs from those studies in that it aims to investigate if WERO (WERO in the Māori language means challenge), a stop smoking contest, using both within team support, external support from a team coach and cessation experts, and technology, would be effective in prompting quitting and increasing abstinence from smoking.

\section{Methods}

\section{WERO - the intervention}

WERO utilises several behaviour change strategies: incentives, competition, social support, behavioural therapy, pharmacological therapy and an interactive website and iPad application (app). Teams competed against each 
other for three months ( $31^{\text {st }}$ May- $30^{\text {th }}$ August 2012) to win a NZ\$5000 (about $€ 3,000, £ 2600$, US\$4000) prize to go to a charity or community group of their choice. Each team had to appoint their own coach (a non-smoker or ex-smoker) from their community. WERO co-ordinators assisted coaches to support their teams to stop smoking, to access cessation workers and pharmacotherapy and coordinators found in-kind support or spot prizes from within the community, such as free access to the public swimming pool, or retail vouchers from a sporting goods store. All WERO co-ordinators received training in how WERO works, their role, how to inform participants, obtain consent and collect data including exhaled carbon monoxide $(\mathrm{CO})$ readings.

\section{Technology}

An interactive website and iPad app was used to strengthen the sense of team and inter-team competitiveness by making the smoking status of team members, and the team, publicly visible. Coaches updated participant smoking status weekly to the study website www.wero.me where each team had their own page.

The website also provided the participants with the opportunity to post to their team page and for supporters to post encouragement. Participants' questions or comments, for example, about withdrawal symptoms and trigger situations, were answered and commented on by medical or cessation experts on the study team.

\section{Recruitment}

WERO teams were recruited via community and health promotion workers from three organisations: Northland District Health Board (who recruited five rurally based Māori teams), Te Whānau o Waipareira, a Māori health and social services provider, in West Auckland, NZ's biggest city (who recruited five urban Māori teams), and a Pacific Island churches healthy lifestyles programme, Enua Ola, in Auckland (who recruited five Pacific Island teams). Some teams included participants of mixed and other ethnicities. The cluster of teams are hereto forth referred to as Rural Māori, Urban Māori and Pacific. For each cluster, WERO co-ordinators were appointed to recruit teams from their community networks over six weeks (from mid-April until $31^{\text {st }}$ May of 2012). In Northland, this involved the co-ordinator approaching individuals in community groups such as sports clubs, kapa haka groups, marae (traditional Māori meeting locations) and small communities. For Pacific, the WERO co-ordinator approached key members of the church communities to recruit teams. Urban Māori teams were formed from staff within different business units within Te Whānau o Waipereira, a church group, a mums and babies group and a family group.

\section{Inclusion criteria}

People were eligible to participate if they were aged 18 years and over, identified as smokers and had an exhaled $\mathrm{CO}$ rating greater than 6 parts per million (ppm), measured with a Bedfont Smokerlyser. The intervention was focused on Māori and Pacific Island people. However, it was a desired criterion, not an inclusion criteria per se.

\section{Exclusion criteria were}

People who could not provide written consent, nonsmokers or smokers whose exhaled CO was less than or equal to $6 \mathrm{ppm}$ at entry were excluded from the study.

\section{Participants}

Fifteen teams of 10 were to be recruited. Assuming $80 \%$ power, $5 \%$ significance, 1 -sided test, no design effect, and a standard treatment 3 month quit rate of $24 \%$ (from the National Quitline), the study needed approximately 100 people to detect a target 3 month quit-rate of $35 \%$. However, because the drop-out rate at follow-up is assumed to be high (50\% from past studies), 150 smokers were recruited. For one team, two contestants stopped smoking prior to completing the eligibility screening and were hence deemed ineligible. Therefore, there were 14 teams with 10 contestants and one team with eight contestants, a total of 148 participants.

\section{Measures}

At the end of competition and at follow-up, six months after the start of competition, contestants were asked "In the last 7 days have you smoked a cigarette (even a puff)?" However, interventions that use competitions or incentives suffer from high levels of deception [21]. Therefore, smoking status was biochemically validated at competition entry to determine eligibility, and at the end of the competition at 3 months to verify self-reported smoking status. Biochemical validation of smokefree status was undertaken using exhaled $\mathrm{CO}$ testing. For a contestant at the end of competition to be deemed to have quit smoking they had to have answered 'No' to the question "In the last 7 days have you smoked a cigarette (even a puff)?" and have an CO reading equal to or below $6 \mathrm{ppm}$ (MacLaren et al. [36]). CO testing was chosen for pragmatic reasons, namely its low cost, ease of use and its availability for healthcare providers.

In addition, participants self-completed questionnaires, containing questions about gender, ethnicity, age, marital status and education level. Also to get feedback on the competition the following questions were included: In your opinion, what makes WERO successful? Tick box options were: Getting support to stop smoking; Getting to raise money for a good cause; Being in a competition; Stopping smoking in a team; and a free text option. Lastly, participants were asked to write about what did 
not work so well with the WERO competition and what could be done to improve it. The qualitative work adheres to the qualitative research reviews guidelines.

Lastly, qualitative interviews were conducted with coordinators and one coach from each cluster of teams at the completion of the 3 month data collection. The interviews included questions on intervention implementation, acceptability and satisfaction with the intervention, identification of barriers for effective implementation, and suggestions for improvement.

\section{Data analysis}

The raw data was entered into an EXCEL spreadsheet and exported to SAS v 9.2 (Cary NY). Intention to treat analysis was used for all quit-rate calculations, that is, those lost to follow-up were assumed to be smoking. To determine the baseline predictors of those who quit at 6 months we used general estimating equation (GEE) analysis to account for correlation within teams and added a region variable (i.e., 5 teams each were nested within 3 clusters) into the model statement. Our model included ethnicity, gender, age (less than or equal to 26 years versus over 26 years), time to first cigarette (less than or equal to 30 minutes versus more than 30 minutes), and region. We chose the exchange structure (also known as compound symmetry) for the correlation matrix because it had a lower QIC score (Quasi-likelihood Information Criterion) than other structures.

The qualitative data was deductively analysed. Summary data were calculated for the participants' quantitative interview questions.

\section{Ethical approval}

Ethical approval was obtained through the Northern X Regional Ethics Committee, reference number NTX/11/ $\mathrm{EXP} / 308$. Due to the public nature of the contest, participants smoking status was not kept confidential. However, all other data collected were confidential. All data were analysed anonymously. Informed consent was administered by the regional co-ordinators.

\section{Results}

\section{Participant demographics}

The age range of participants was 16 to 70 years old, with a mean of 38 years, 53\% were Māori and nearly 60\% were women (Table 1). On average contestants smoked 15.6 cigarettes per day. Many (71\%) had their first cigarette within 30 minutes of waking up, indicating a high level of addiction. Thirty-seven per cent had never tried to quit before.

\section{Main outcomes}

At the end of competition the biochemically verified 24hour quit rate was 36\% (95\% CI: 28\%-44\%) (Table 2). The
Table 1 Participant demographics (\% may not add to $100 \%$ because of rounding)

\begin{tabular}{lc}
\hline Variable & Count (\%) \\
\hline Ethnicity & $78(53 \%)$ \\
Māori & $32(22 \%)$ \\
Samoan & $4(3 \%)$ \\
Cook Island Māori & $10(7 \%)$ \\
Tongan & $7(5 \%)$ \\
Niuean & $4(3 \%)$ \\
Other Pacific & $11(7 \%)$ \\
European & $2(1 \%)$ \\
Indian & \\
Gender & $60(41 \%)$ \\
Men & $88(59 \%)$ \\
Women & \\
Age & $18(11 \%)$ \\
15-24 & $59(36 \%)$ \\
$25-34$ & $33(20 \%)$ \\
$35-44$ & $40(24 \%)$ \\
$45-54$ & $10(6 \%)$ \\
$55+$ & $6(4 \%)$ \\
Missing & $85(57 \%)$ \\
Cigarettes smoked per week day & $55(37 \%)$ \\
Time until first cigarette & $8(5 \%)$ \\
Aithin 5 minutes 60 minutes 60 minutes & $6(45.6$ \\
Missing & $59(40 \%)$ \\
Previous quit attempt & $16(11 \%)$ \\
\hline
\end{tabular}

Table 27 day point prevalence at 3 and 6 months follow-up

\begin{tabular}{lccccc}
\hline & \multicolumn{2}{c}{$\mathbf{3}$ months } & & \multicolumn{2}{c}{$\mathbf{6}$ months } \\
\cline { 2 - 3 } \cline { 5 - 6 } \cline { 5 - 6 } & Count & \% & & Count & $\%$ \\
\hline Not smoking & 53 & $36 \%$ (quit-rate) $^{\dagger}$ & & 39 & $26 \%$ (quit-rate) $^{\ddagger}$ \\
Smoking & 74 & $50 \%$ & & 81 & $55 \%$ \\
$\begin{array}{l}\text { Did not complete } \\
\text { question }\end{array}$ & 1 & $0 \%$ & & 0 & $0 \%$ \\
$\begin{array}{l}\text { Lost to follow-up } \\
\text { (Dropout rate) }\end{array}$ & 20 & $14 \%$ & & 28 & $19 \%$ \\
Total & $\mathbf{1 4 8}$ & $\mathbf{1 0 0 \%}$ & & $\mathbf{1 4 8}$ & $\mathbf{1 0 0 \%}$ \\
\hline
\end{tabular}

${ }^{\dagger}$ Biochemically verified.

${ }^{\ddagger}$ Self-report only not biochemically verified. 
6 months self-reported quit rate was 26\% (95\% CI: 20\%$34 \%)$. At competition end, loss to follow-up was $14 \%$ (21/ $148)$ and $19 \%(28 / 148)$ at 6 months.

Those aged 26 years and older were significantly more likely $(\mathrm{OR}=1.99,95 \% \mathrm{CI} 1.08-3.64)$ to self-report being quit smoking at 6 months follow-up compared to younger participants (Table 3 ).

\section{Team and cluster of teams outcomes}

The urban Māori teams had more participants that were 26 years old or younger, than the rural Māori or Pacific teams (Table 4). Pacific had a high rate $(80 \%)$ of smokers who had never quit before, compared to $19 \%$ and $12 \%$ for the Māori urban and rural teams.

The number of quitters per team ranged from zero (no quitters) to ten (all quit). Three teams had no quitters and one team had ten quitters. The average number of quitters per team was 3.5 and the median number of quitters per team was 3 . The Pacific teams had the highest overall quit rate at both end of competition and at 6months follow-up (Table 5). However, the winning team, with 10 out of 10 quitters, were a rural Māori team. The urban Māori teams had substantially lower quit rates at both end of competition and 6-months follow-up than the rural Māori or Pacific teams.

\section{Co-ordinators', coaches' and contestants' views}

All coaches and co-ordinators expressed great satisfaction and acceptability of the intervention, including a coach from and the co-ordinator of the Māori urban teams that did not have as many quitters.

I think it's [WERO] great!... It's going to help get people going and it's going to motivate people to have a go. (Rural Māori coach)

Table 3 GEE logistic regression model $(n=148$ ) (accounting for correlation within teams and a region effect, exchange matrix and QIC = 175.096) with outcome those who quit cigarettes at 6 months follow-up and covariates: ethnicity, gender, age, and time to first cigarette

\begin{tabular}{lccc}
\hline Variable & Beta estimate & SE & P-value \\
\hline Māori versus Others & 0.718 & 0.981 & 0.4640 \\
Pacific versus Others & -2.043 & 1.630 & 0.2100 \\
Female versus Male & 0.323 & 0.234 & 0.1682 \\
Age; Under or equal to & 0.686 & 0.309 & 0.0264 \\
26 versus over 26 years & & & \\
Time to first cigarette & 0.084 & 0.171 & 0.6233 \\
(mins) 30+ versus under 30 & & & \\
Pacific versus Urban Māori & 3.648 & 2.040 & 0.0738 \\
Rural Māori versus Urban Māori & 0.725 & 0.441 & 0.1002 \\
\hline
\end{tabular}

The idea [WERO] is absolutely fantastic... for us Pacific and Màori people because ... one person will look at the other person, you know and copy what he does, one quits and the other one will follow. (Pacific co-ordinator)

It was identified that the concept of WERO could be applicable in other areas also.

I think it was a good platform for us to look at other things as well, like a good model I should say for us. You can use it in any environment, or any group organisation (Rural Māori Co-ordinator)

A number of contestants provided very positive feedback.

Thanks to this programme cause it helped me stop smoking and working as a team was great.

I have no idea how you could improve the comp. But I do know, that, this kaupapa [programme] works. I have been smoking longer than most of the members in my haka roopu [kapa haka group] and now I'm smokefree.

The most common activities that the contestants found helpful were support, from each other, the team coach and WERO co-ordinators, and getting together and competing against other teams (Table 6a). The rural Māori teams particularly found the within team support and support from coaches and co-ordinators helpful, while more of the Pacific teams selected getting together as helpful. Only 7\% of participants didn't take part in the activities, nearly all from the urban Māori teams, and only $2 \%$ did not find any of the activities helpful, all from the urban Mãori teams.

Over $90 \%$ of participants selected one of more options as successful, 27\% of participants did not select any options as successful and three participants stated that nothing was successful with WERO (Table 6b). The most commonly selected options were getting support to stop smoking and stopping smoking in a team.

Coaches, co-ordinators and contestants (Table 6a) identified that between-teams contest was most important.

Oh that's [between team competition] really important... if all the regional teams know each other then that would make it a bit more competitive.

(Urban Māori co-ordinator)

Yeah, I think it was very important to know that there are other teams as well in the competition and for everyone to try and stop smoking (Pacific coach) 
Table 4 Participants demographic by Region

\begin{tabular}{|c|c|c|c|c|}
\hline & Pacific count (col\%) & Rural Māori count (col\%) & Urban Māori count (col\%) & Total count (col\%) \\
\hline Total & $50(100 \%)$ & $48(100 \%)$ & $50(100 \%)$ & $148(100 \%)$ \\
\hline \multicolumn{5}{|l|}{ Ethnicity } \\
\hline Māori & 0 & $43(90 \%)$ & $35(69 \%)$ & 78 (53\%) \\
\hline Samoan & $30(60 \%)$ & 0 & $2(4 \%)$ & $32(22 \%)$ \\
\hline Cook Island Māori & $1(2 \%)$ & 0 & $3(6 \%)$ & $4(3 \%)$ \\
\hline Tongan & $10(20 \%)$ & 0 & 0 & $10(7 \%)$ \\
\hline Niuean & $7(14 \%)$ & 0 & 0 & $7(5 \%)$ \\
\hline Other Pacific & $2(4 \%)$ & 0 & $1(2 \%)$ & $3(2 \%)$ \\
\hline European & 0 & $5(10 \%)$ & $6(12 \%)$ & $11(7 \%)$ \\
\hline Indian & 0 & 0 & $3(6 \%)$ & $3(2 \%)$ \\
\hline \multicolumn{5}{|l|}{ Gender } \\
\hline Men & $30(60 \%)$ & $19(40 \%)$ & $11(22 \%)$ & $60(41 \%)$ \\
\hline Women & $20(40 \%)$ & $29(60 \%)$ & $39(78 \%)$ & $88(59 \%)$ \\
\hline \multicolumn{5}{|l|}{ Age } \\
\hline $15-24$ & $1(2 \%)$ & $4(8 \%)$ & $13(26 \%)$ & $18(12 \%)$ \\
\hline 25-34 & $11(22 \%)$ & $16(33 \%)$ & $14(28 \%)$ & $41(28 \%)$ \\
\hline $35-44$ & $16(32 \%)$ & $8(17 \%)$ & $9(18 \%)$ & $33(22 \%)$ \\
\hline $45-54$ & $20(40 \%)$ & $12(25 \%)$ & $8(16 \%)$ & $40(27 \%)$ \\
\hline $55+$ & $2(4 \%)$ & $6(13 \%)$ & $2(4 \%)$ & $10(7 \%)$ \\
\hline Missing & 0 & $2(4 \%)$ & $4(8 \%)$ & $6(4 \%)$ \\
\hline \multicolumn{5}{|c|}{ Cigarettes smoked per day } \\
\hline Week day & $16\left(\mathrm{IQR}^{*}=12\right)$ & $17\left(\mathrm{IQR}^{*}=12\right)$ & $13\left(\mathrm{IQR}^{*}=12\right)$ & $16\left(\mathrm{IQR}^{*}=12\right)$ \\
\hline Weekend day & $16\left(\mathrm{QQR}^{*}=12\right)$ & $20\left(\mathrm{IQR}^{*}=15\right)$ & $15\left(\mathrm{IQR}^{*}=10\right)$ & $17\left(\mathrm{IQR}^{*}=10\right)$ \\
\hline \multicolumn{5}{|c|}{ Time to first cigarette } \\
\hline $1=$ within 5 mins & $14(28 \%)$ & $14(29 \%)$ & $18(36 \%)$ & $46(31 \%)$ \\
\hline $2=6-30 \mathrm{mins}$ & $25(50 \%)$ & $17(35 \%)$ & $17(34 \%)$ & $59(40 \%)$ \\
\hline $3=31-60 \mathrm{mins}$ & $5(10 \%)$ & $5(10 \%)$ & $6(12 \%)$ & $16(11 \%)$ \\
\hline $4=$ after $60 \mathrm{mins}$ & $6(12 \%)$ & $8(17 \%)$ & $7(14 \%)$ & $21(14 \%)$ \\
\hline Missing & 0 & $4(8 \%)$ & $2(4 \%)$ & $6(4 \%)$ \\
\hline \multicolumn{5}{|c|}{ Previous quit attempt } \\
\hline Yes & $9(18 \%)$ & $35(73 \%)$ & $41(82 \%)$ & $85(57 \%)$ \\
\hline No & $40(80 \%)$ & $9(19 \%)$ & $6(12 \%)$ & $55(37 \%)$ \\
\hline Missing & $1(2 \%)$ & $4(8 \%)$ & $3(6 \%)$ & $8(5 \%)$ \\
\hline
\end{tabular}

*IQR $=$ inter-quartile range (i.e., $T$ The $75^{\text {th }}$ minusthe $25^{\text {th }}$ percentiles).

Table 5 Quit and Dropout rates by cluster of teams

\begin{tabular}{|c|c|c|c|c|c|c|}
\hline & \multicolumn{2}{|c|}{ Pacific } & \multicolumn{2}{|c|}{ Rural Māori } & \multicolumn{2}{|c|}{ Urban Māori } \\
\hline & 3-month & 6-month & 3-month & 6-month & 3-month & 6-month \\
\hline Quit rate & $46 \%(23 / 50)$ & $36 \%(18 / 50)$ & $44 \%(21 / 48)$ & $29 \%(14 / 48)$ & $18 \%(9 / 50)$ & $14 \%(7 / 50)$ \\
\hline Dropout rate & $4 \%$ & $4 \%$ & $13 \%$ & $11 \%$ & $26 \%$ & $42 \%$ \\
\hline
\end{tabular}


Table 6 Acceptability and success of WERO

\begin{tabular}{|c|c|c|c|c|c|c|c|c|}
\hline & \multicolumn{2}{|c|}{ Overall } & \multicolumn{6}{|c|}{ By group } \\
\hline & \multirow[b]{2}{*}{ Count } & \multirow[b]{2}{*}{$\%$} & \multicolumn{2}{|c|}{ Pacific } & \multicolumn{2}{|c|}{ Urban Māori } & \multicolumn{2}{|c|}{ Rural Māori } \\
\hline & & & Count & $\%$ & Count & $\%$ & Count & $\%$ \\
\hline \multicolumn{9}{|l|}{ a) Helpful activities } \\
\hline Supporting each other & 50 & $39 \%$ & 14 & $29 \%$ & 13 & $35 \%$ & 23 & $53 \%$ \\
\hline Support from our team coach & 48 & $38 \%$ & 14 & $29 \%$ & 12 & $32 \%$ & 22 & $51 \%$ \\
\hline Support from WERO co-ordinator & 48 & $38 \%$ & 18 & $38 \%$ & 5 & $14 \%$ & 25 & $58 \%$ \\
\hline Support from a stop smoking advisor & 10 & $8 \%$ & 1 & $2 \%$ & 2 & $5 \%$ & 7 & $16 \%$ \\
\hline Support from whānau & 6 & $5 \%$ & 0 & $0 \%$ & 0 & $0 \%$ & 6 & $14 \%$ \\
\hline Socialising together & 38 & $30 \%$ & 20 & $42 \%$ & 7 & $19 \%$ & 11 & $26 \%$ \\
\hline Meeting together & 42 & $33 \%$ & 21 & $44 \%$ & 5 & $14 \%$ & 16 & $37 \%$ \\
\hline Sharing our stories & 26 & $20 \%$ & 8 & $17 \%$ & 6 & $16 \%$ & 12 & $28 \%$ \\
\hline Making a commitment to our group & 35 & $27 \%$ & 9 & $19 \%$ & 7 & $19 \%$ & 19 & $44 \%$ \\
\hline Competition within team & 16 & $13 \%$ & 6 & $13 \%$ & 4 & $11 \%$ & 6 & $14 \%$ \\
\hline Competing against other teams & 40 & $31 \%$ & 20 & $42 \%$ & 9 & $24 \%$ & 11 & $26 \%$ \\
\hline Don't know & 6 & $5 \%$ & 2 & $4 \%$ & 2 & $5 \%$ & 2 & $5 \%$ \\
\hline I did not take part in any activities & 9 & $7 \%$ & 0 & $0 \%$ & 7 & $19 \%$ & 2 & $5 \%$ \\
\hline I did not find any of these helpful & 2 & $2 \%$ & 0 & $0 \%$ & 2 & $5 \%$ & 0 & $0 \%$ \\
\hline \multicolumn{9}{|l|}{ b) Successful WERO elements } \\
\hline Selected at least one & 116 & $91 \%$ & 45 & $94 \%$ & 30 & $81 \%$ & 41 & $95 \%$ \\
\hline Didn't select any option & 34 & $27 \%$ & 3 & $6 \%$ & 7 & $19 \%$ & 2 & $5 \%$ \\
\hline Said "nothing was successful" & 3 & $2 \%$ & 0 & $0 \%$ & 3 & $8 \%$ & 0 & $0 \%$ \\
\hline \multicolumn{9}{|l|}{ Options selected } \\
\hline Getting support to stop smoking & 74 & $58 \%$ & 16 & $33 \%$ & 21 & $57 \%$ & 37 & $86 \%$ \\
\hline Raising money for a good cause & 55 & $43 \%$ & 21 & $44 \%$ & 8 & $22 \%$ & 26 & $60 \%$ \\
\hline Being in a competition & 45 & $35 \%$ & 13 & $27 \%$ & 11 & $30 \%$ & 21 & $49 \%$ \\
\hline Stopping smoking in a team & 69 & $54 \%$ & 22 & $46 \%$ & 14 & $38 \%$ & 33 & $77 \%$ \\
\hline
\end{tabular}

Competing against teams from other clusters and Māori versus Pacific was also important:

We always saw it as a Tai Tokerau [Northland] vs Tāmaki [Auckland] thing. (Rural Māori Co-ordinator)

Only 31 contestants provided any criticism of WERO. The most common critiques of WERO, from both coaches, co-ordinators and contestants was difficulty in getting team members together. Some contestants reported that there was lack of commitment $(n=4)$ or support ( $n=4$ ) from team members, and difficulty in attending meetings $(\mathrm{n}=3)$. Coaches and co-ordinators also stated difficulties getting some teams together.

Towards the end I just got really hoha (annoyed) cause it was a real hassle trying to get them there but they were really over it. (Urban Mãori coach)
Challenges. It is getting everybody together to meet. (Rural Māori coach)

Even though they were keen to participate and be involved, it was really hard to get them all together in one place... One of the things that worked to do that was when they had their wānanga [educational training workshops] every month. (Rural Mäori co-ordinator)

Another criticism from coaches was the limited time prior to the start of the contest for coaches to prepare.

It happened all a bit quickly; in the beginning we really didn't have time to sit down and organise sessions etc. properly. (Rural Māori coach)

Probably the timing as well. More warnings and that would be really good. (Pacific coach) 
An Urban Mãori coach thought that the contest wasn't long enough, while the rest of the coaches and coordinators thought that the length was just right.

It's probably not long enough cause even if you're just working with people and you know you'll have a drop off period maybe I think 3 months is too short. (Urban Māori coach)

I think 3 months is perfect... if it's earlier, it wouldn't of given heaps of people a chance to become a non-smoker. So I think 3 months is good. (Urban Māori co-ordinator)

There were also some technical difficulties. Three contestants had no access to technology $(n=3)$. Some teams didn't have internet access.

So actually another challenge was a lot of people didn't have internet. (Urban Māori coach)

There were also some concerns about the $\mathrm{CO}$ testing:

The carbon testing thing, I don't think it was accurate (Urban Māori coach)

Only 31 participants provided any suggested improvements. The most common suggestion $(n=11)$ was for more prizes, for example, some prize for all who managed to get smokefree, smaller prizes at regular intervals of the competition and gifts for all participants.

\section{Maybe even if all of the team would get something. That that would be... even if just a small prizes for every team and they would be very appreciative. (Pacific Co-ordinator)}

Contestants, co-ordinators and coaches suggested more activities, within teams, with WERO support staff and with other teams.

We could have all met one another, scoped out our competition but we're all disconnected. (Urban Mãori coach)

\section{Discussion}

WERO achieved a high quit rate among a high smoking prevalence group. Compared to the national quitting rate (19\% for Māori and 14\% for Pacific for supported quitting at 6-months follow-up [37]), and previous Quit and Win contests (for example [19]) the WERO end of competition quit rate was high. It should be noted that the design of WERO limits the comparability with previous Quit and Win contests [21-24], since those studies were conducted with more rigorous design. However, given the high smoking prevalence and non-significant reduction in smoking prevalence for Māori (remaining at 41\%) or Pacific Island people (remaining at 26\%) [2], WERO appeared to also be successful in achieving a high 6month self-reported follow-up quit rate. Contestants, team coaches and WERO co-ordinators found the intervention acceptable. They particularly liked the group aspect and the inter-team competition. Recruitment of Indigenous people into research interventions can often be problematic [38], but was successful over a short recruitment period for WERO. WERO was informed by Māori culture, but findings should be of interest to other cultures who are family-centred and competitive also. This is of particular relevance, since many other countries, such as the USA, Canada and Australia, have disproportionately high smoking prevalence among their Indigenous, Pacific and Asian people. Furthermore, previous research has identified that friendly competition can be an effective element in health interventions for Indigenous people [39].

The findings from this study support previous work [30-33,40-42] that highlighted the importance of social support in Quit and Win contests. However, the difference between WERO and, for example, Croghan, O'Hara, Schroeder, et al. [33] was that the team members were both smokers and supporters. Previous workplace Quit and Win team contests [22-24], achieved high end-ofcompetition quit rates, but were not successful in achieving significantly higher follow-up quit rates. One potential explanation for the high 6-month follow-up quit rate in WERO, is that the teams were mostly made up of existing groups with close ties, who may have been able to continue to support each other. The use of technology in WERO potentially increased the support contestants received from their team members and also cessation experts. It also provided a forum where contestants could engage with other teams, the competitive element could be built upon, and contestants could gain a sense of being part of the efforts of many others to quit. Māori are early adopters of technology: $78 \%$ of Māori have access to a computer with internet and $87 \%$ have a cell phone or PDA [43]. The number of online health interventions is rapidly increasing and is showing promise in changing behaviour [44].

WERO has subsequently been funded to run a series of country wide competitions that will be made up of smaller regional or inter-regional competitions. There is no limit to the total number of teams that can register in concurrent competitions, thus enabling mass quitting to occur. Further, WERO has been designed to be used by organisations at a number of levels from health providers down to local providers and community groups. WERO is a voluntary removal of demand from tobacco products. 


\section{Strengths and limitations}

The main strength of this study was that the intervention was informed by the needs of the target audience, identified in previous research by the authors. The intervention was innovative in its use of new technology (e.g. apps) applied at a community level. This fitted with the New Zealand Tobacco Control Research Tūranga brief for research to be innovative, pragmatic, able to demonstrate a strong link to rapid prevalence reduction, be relatively short in duration from conception to delivering of results and have the potential to be scaled up. The requirement to conduct shorter studies imposes some limitations. Strongly powered randomised controlled trials, for instance, are beyond the scope and budget available to the Turanga. Hence the short-term pre and post study non-randomised design used here. One limitation of the research design, is that it was not possible to control for confounders, such as the impact of individual coordinators or coaches. The design also limits the comparability of WERO to previous Quit and Win contests [19] and previous workplace studies [19,22-24], since those studies were conducted in different countries and with more rigorous design. Our study also lacked a control group so it is difficult to ascertain how much of the high quit rate was due to the external environment rather than the intervention itself. However, as far as we are aware, there were no major significant tobacco control policies, such as tax increases, during the intervention period. Endof-competition smoking status in this study was ascertained using $\mathrm{CO}$ tests. Given that $\mathrm{CO}$ levels only assess smoking in the preceding nine hours, it is possible that the quit rates reported in this study are an overestimate. Cotinine tests would have provided a more reliable assessment of smoking cessation, however, it was not feasible in this study due to costs. Lastly, 6-month follow-up relied on self-report and was not biochemically verified. This could also potentially overestimate the quit rate.

\section{Future work}

The limitations of this study highlight the need for future controlled trials with longer follow-up times of team based cessation contests like WERO. The survey and interview data suggests that the group element and social support were particularly satisfactory for the contestants, while the prize structure may not have been optimal. While some teams thought that it was ideal to donate the prize to a charity, others would have liked to receive the prize themselves. The WERO intervention comprised several behaviour change strategies but the design of the study precluded independent assessment of the relative contribution of each. Future controlled studies need to be conducted that allow for assessment of the individual elements, as well as the influence of coordinators or coaches. It would be useful to investigate if
WERO would be as effective with other populations, for example Indigenous populations in other countries, or pregnant smokers. It is also possible that this intervention could be modified to trigger change in other health related behaviours, such as physical activity and nutrition. Lastly, it would be useful to conduct future work to establish cost-effectiveness and the cost per quitter of running this type of intervention.

\section{Conclusion}

If NZ is to reach its smokefree nation goal by 2025, innovative tobacco control strategies that can induce rapid reduction in smoking prevalence within existing health budgets are needed. Groups based quit competitions, like WERO, offer one such solution.

\section{Competing interests}

The authors declare that they have no competing interests.

\section{Authors' contributions}

MG conceived of the study and was involved in all aspects of the study. AK participated in design of study, review of literature and critical revisions of the manuscript. DG and AK conducted the analysis. NC, CP and WM participated in design of study, website and iPad application and development of other study materials and documents. They provided input into and critical review of the manuscript. All authors read and approved the final manuscript.

\section{Acknowledgement}

WERO is one project being undertaken as part of New Zealand's Tobacco Control Research Tūranga: A programme of innovative research to halve smoking prevalence in Aotearoa/New Zealand within a decade. The Tūranga is supported through funding from the Reducing Tobacco-related Harm Research Partnership co-funded by the Health Research Council of New Zealand and the Ministry of Health of New Zealand (HRC grant 11/818). WERO collaborators included: Julia Choi at Te Whānau o Waipareira, Faaoso Setu at the Waitemata District health board funded Enua Ola programme, and Ralph Ruka the Northland District Health Board Healthy Lifestyles team. We would also like to acknowledge Amber Bosman, an intern from Wageningen University, who worked on the WERO study team for four months. Furthermore, we would like to thank Catherine Dowson and Alehandrea Manuel for drafting an earlier literature review.

\section{Author details}

${ }^{1}$ Centre for Tobacco Control Research, Social and Community Health, University of Auckland, Auckland, New Zealand. ${ }^{2}$ George Centre for Healthcare Innovation, University of Oxford, Richard Doll Building, Old Road Campus, Roosevelt Drive, Oxford OX3 7LF, England. ${ }^{3}$ Healthy Lifestyles Team, Northland District Health Board, Auckland, New Zealand.

Received: 13 November 2013 Accepted: 4 June 2014

Published: 13 June 2014

\section{References}

1. Cancer Society of Finland: Health Promotion. 2013. 2010, from http://www. cancer.fi/en/activities/health/.

2. Ministry of Health: The Health of New Zealand Adults 2011/12: Key findings of the New Zealand Health Survey. Wellington: Ministry of Health; 2012.

3. Picco L, Subramaniam M, Abdin E, Vaingankar JA, Chong SA: Smoking and nicotine dependence in Singapore: Findings from a cross-sectional epidemiological study. Ann Acad Med Singapore 2012, 41(8):325-334. doi:Retrieved from http://www.annals.edu.sg/pdf/41VolNo8Aug2012/ V41N8p325.pdf.

4. The Australian Government: 2010 National Drug Strategy Household Survey Report. Canberra, Australia: Austalian Institute of Health and Welfare; 2010. 
5. The Scottish Government: Health of Scotlands Population: Smoking. Retrieved 12 June, 2013, from http://www.scotland.gov.uk/Topics/Statistics/ Browse/Health/TrendSmoking.

6. Statistics New Zealand: Quitting and not starting - smoking in New Zealand decreases. 2014, http://www.stats.govt.nz/Census/2013-census/ data-tables/totals-by-topic-mr2.aspx

7. New Zealand Government: Government Final Response to Report of the Māori Affairs Committee on Inquiry into the Tobacco Industry in Aotearoa and the Consequences of Tobacco Use for Māori House of Representatives. Wellington: New Zealand Government: House of Representatives; 2011.

8. Group NSWG: Nation Smokefree Working Group: Ministry of Health update Nation Smokefree Working Group. Wellington, NZ: Nation Smokefree Working Group; 2013

9. New Zealand Institute of Economic Research: Smoking targets: A Microsimulation Analysis - Final Report to the Ministry of Health. Wellington, NZ: New Zealand Institute of Economic Research; 2012.

10. Jenkins M: Implementing the ABC Approach for Smoking Cessation: Framework and Work Programme. Wellington: Ministry of Health Tobacco Policy and Implementation Team; 2009.

11. Glover M, Nosa V, Fraser T: KwitNeeds: What Support Do Smokers Need to assist them with Stopping Smoking? Topline Results. Auckland: University of Auckland, School of Population Health, Centre for Tobacco Control Research; 2010.

12. Cowie N, Glover M, Scragg R, Bullen C, Nosa V, McCool J, Gentles D: Awareness and perceived effectiveness of smoking cessation treatments and services among New Zealand parents resident in highly deprived suburbs. N Z Med J 2013, 126(1378):48-59.

13. Thomas SB, Fine MJ, Ibrahim SA: Health disparities: the importance of culture and health communication. Am J Publ Health 2004, 94(12):2050 doi:Retrieved from http://www.ncbi.nlm.nih.gov/pmc/articles/PMC1448585/ pdf/0942050.pdf.

14. Sport and Recreation New Zealand: Sport, Recreation and Physical Activity Participation among New Zealand Adults: Key Results of the 2007/08 Active New Zealand Survey. Wellington: SPARC; 2008.

15. Sakamoto H: Researching Kapa Haka and its educational meanings in today's Aotearoa/New Zealand: weaving methodologies, perspectives and decency. Int J Arts Soc 2012, 6(3):57-66.

16. Spoonley P, Taiapa C: Sport and Cultural Diversity: Responding to the Sports and Leisure Needs of Immigrants and Ethnic Minorities in Auckland. Prepared for Auckland Regional Physical Activity and Sport Strategy (ARPASS). Auckland: Massey University; 2009.

17. Parker EA, Meiklejohn B, Paterson C, Edwards K, Preece C, Shuter P, Gould T: Our games our health: A cultural asset for promoting health in Indigenous communities. Health Promot J Austr 2006, 17(2):103-108. doi:10.1071/HE06103.

18. Glover M, Nosa V, Watson D, Paynter J: WhyKwit: A Qualitative Study of What Motivates Mäori, Pacific Island and Low Socio-Economic Peoples in Aotearoal New Zealand to Stop Smoking. Auckland: University of Auckland, School of Population Health, Centre for Tobacco Control Research; 2010.

19. Cahill K, Perera R: Quit and Win contests for smoking cessation. Cochrane Database Syst Rev 2008, 4:1-22. doi:10.1002/14651858CD004986.pub3.

20. Jepson RG, Harris FM, Platt S, Tannahill C: The effectiveness of interventions to change six health behaviours: A review of reviews. BMC Public Health 2010, 10. doi:10.1186/1471-2458-10-538.

21. Cahill K, Perera R: Competitions and incentives for smoking cessation. Cochrane Database Syst Rev 2011, (4):CD004307. doi:10.1002/14651858. CD004307.

22. Klesges RC, Glasgow RE, Klesges LM: Competition and relapse prevention training in worksite smoking modification. Health Educ Res 1987, 2(1):5-14. doi:10.1093/her/2.1.5.

23. Klesges RC, Vasey MM, Glasgow RE: A worksite smoking modification competition: Potential for public health impact. Am J Public Health 1986, 76(2):198-200. doi: Retrieved from http://www.ncbi.n/m.nih.gov/pmc/ articles/PMC1646475/pdf/amjph00265-0088.pdf.

24. Maheu MM, Gevirtz RN, Sallis JF, Schneider NG: Competition/cooperation in worksite smoking cessation using nicotine gum. Prev Med 1989, 18(6):867-876. doi:10.1016/0091-7435(89)90022-4

25. Jeffery RW, Gerber WM, Rosenthal BS, Lindquist RA: Monetary contracts in weight control: Effectiveness of group and individual contracts of varying size. J Consult Clin Psychol 1983, 51(2):242-248. doi:10.1037/0022006X.51.2.242.
26. Kullgren JT, Troxel AB, Loewenstein G, Asch DA, Norton LA, Wesby L, Volpp KG: Individual-versus group-based financial incentives for weight loss, A randomized, controlled trial. Ann Intern Med 2013, 158(7):505-514. doi:10.7326/0003-4819-158-7-201304020-00002.

27. Paul-Ebhohimhen $V$, Avenell A: Systematic review of the use of financial incentives in treatments for obesity and overweight. Obes Rev 2008, 9(4):355-367. doi:10.1111/j.1467-789X.2007.00409.X.

28. Van Den Putte B, Yzer M, Southwell BG, De Bruijn GJ, Willemsen MC: Interpersonal communication as an indirect pathway for the effect of antismoking media content on smoking cessation. J Health Comm 2011, 16(5):470-485. doi:10.1080/10810730.2010.546487.

29. McDonald PW: Population-based recruitment for quit-smoking programs: An analytic review of communication variables. Prev Med 1999, 28(6):545-557. doi:10.1006/pmed.1998.0479.

30. Bains N, Pickett W, Laundry B, Mecredy D: Predictors of smoking cessation in an incentive-based community intervention. Chronic Dis Can 2000, 21(2):54-61. doi:Retrieved from http://www.ncbi.n/m.nih.gov/pubmed/ 11007655 .

31. Van Osch L, Lechner L, Reubsaet A, Steenstra M, Wigger S, De Vries H: Optimizing the efficacy of smoking cessation contests: an exploration of determinants of successful quitting. Health Educ Res 2009, 24(1):54-63. doi:10.1093/her/cym090.

32. Pirie PL, Rooney BL, Pechacek TF, Lando HA, Schmid LA: Incorporating social support into a community-wide smoking-cessation contest. Addict Behav 1997, 22(1):131-137. doi:10.1016/0306-4603(95)00106-9.

33. Croghan IT, O'Hara MR, Schroeder DR, Patten CA, Croghan GA, Hays JT, Hurt RD: A community-wide smoking cessation program: quit and win 1998 in Olmsted County. Prev Med 2001, 33:229-238. doi:10.1006/ pmed.2001.0883.

34. Wilson N: Review of the Evidence for Major Population-Level Tobacco Control Intervention. Wellington: Ministry of Health; 2007.

35. Glover M, Bosman A, Wagemakers A, Kira A, Paton C, Cowie N: An innovative team-based stop smoking competition among Māori and Pacific Island smokers: rationale and method for the study and its evaluation. BMC Public Health 2013, 13(1):1-8. doi:10.1186/1471-2458-13-1228.

36. MacLaren D, Conigrave K, Robertson J, Ivers R, Eades S, Clough A: Using breath carbon monoxide to validate self-reported tobacco smoking in remote Australian Indigenous communities. Popul Health Metrics 2010, 8(1):1-7. doi:10.1186/1478-7954-8-2.

37. Gravitas: The Quit Group - Longitudinal Survey: Six-Month Survey Full Report. Auckland, New Zealand: Gravitas Research and Strategy Limited; 2012.

38. Glover M, Kira A, Johnston V, Walker N, Thomas DP, Change A, Segan C: Increasing Indigenous participation in randomized controlled trials. Glob Health Promot 2014, In Press.

39. Teufel-Shone NI: Promising strategies for obesity prevention and treatment within American Indian communities. J Transcult Nurs 2006, 17(3):224-229. doi:10.1177/1043659606288378.

40. Korhonen T, McAlister A, Laaksonen M, Laatikainen T, Puska P: International quit and win 1996: standardized evaluation in selected campaign countries. Prev Med 2000, 31:742-751. doi:10.1006/pmed.2000.0766.

41. Lando HA, Pechacek TF, Fruetel J: The Minnesota Heart Health Program community quit and win contests. Am J Health Promot 1994, 9(2):85-87. http://dx.doi.org/10.4278/0890-1171-9.2.85.

42. Tillgren P, Haglund JA, Ainetdin T, Holm L-E: Who is a successful quitter? One-year follow-up of a National Tobacco Quit and Win Contest in Sweden. Scand J Publ Health 1995, 23:193-201. doi:10.1177/ 140349489502300310

43. Fryer K, Kalafatelis E, Palmer S: New Zealanders' Use of Broadcasting and Related Media. Wellington: Ministry for Culture and Heritage and Te Puni Kōkiri; 2009.

44. Lustria MLA, Cortese J, Noar SM, Glueckauf RL: Computer-tailored health interventions delivered over the web: Review and analysis of key components. Patient Educ Couns 2009, 74(2):156-173. doi:10.1016/j. pec.2008.08.023.

doi:10.1186/1471-2458-14-599

Cite this article as: Glover et al:: The WERO group stop smoking competition: main outcomes of a pre- and post- study. BMC Public Health 2014 14:599. 